\title{
Management of the Interrelationship between Surface Water Quality and Drinking Water Production Process
}

\author{
Mohamed Ahmed Reda Hamed \\ Civil Eng. Department, Canadian International College, Sheikh Zayed City, Giza, Egypt \\ Email: Moha_Hamed@cic-cairo.com.eg
}

\begin{abstract}
The rapid growth of the population in Egypt has made an impact on the portable water demand, which requires exploration of raw water sources, developing treatment and distribution systems. The Ismailia canal represents the most distal downstream of the main Nile River. Thus, its water contains all the proceeded pollutants discharged into the Nile. However, the water treatment plants system along this canal must be modified before application. However, this research is being conducted at two surface water treatment plants (AlAmerya and Mostorud) along the canal. In that manner, to reduce treatment chemical estimation error and consequence obtain the optimal treatment efficiency, this study aims to model the appropriate amount of alum used for the coagulation process taking into consideration the canal surface water quality characteristics. Meanwhile, a predictive nonlinear model for determining the required aluminum sulphate (alum) quantity for studied water treatment plants (WTPs) was developed by considering the interrelationship between canal water quality parameters such as Temperature, $\mathrm{pH}$, Turbidity, and the quantity of Alum required for the mentioned drinking water treatment plants. The model constants were obtained using a least square regression method. Then, many alternative models were developed for quantifying the required alum dosage based on the dominant surface water quality parameters. Comparison of the model simulation with the experimental data showed a good prediction. The study revealed that the optimal coagulant dosing can be predicted from the operating data with accuracy to reduce the number of chemicals being used.
\end{abstract}

Keywords: Surface Water Quality, Nonlinear Model, Water Treatment Plants, Coagulation Process, Alum Dosage.

\section{INTRODUCTION}

The Ismailia Canal is one of the principle sources of drinking water supply for a great number of the citizens in northern and eastern parts of Cairo before entering the Suez Canal Province. The Ismailia Canal is endangered from unwise, direct and indirect activities in the surrounding environments. Microbial contaminants, such as viruses and bacteria, and inorganic and organic contaminants were found in its running water [1].

They have added constraints on the traditional drinking water treatment techniques and have led to the formation of trihalomethanes (THMs) as one of disinfection by products. The choice of treatment method depends on the quality and nature of the raw water, so its process can be as straightforward as sedimentation or with complex physicochemical changes such as coagulation. An important water quality variable that must be considered when selecting or configuring the water treatment sequence is the $\mathrm{pH}$ [2]. This variable has a significant impact on the chemistry of water components and the performance of the treatment process. Therefore, it is important to regularly monitor and control the $\mathrm{pH}$ profile at all water treatment stages. The most commonly used coagulant is aluminum sulphate which is commonly called alum because of its lower cost and its widespread availability.

The effectiveness of coagulants varies greatly depending on the $\mathrm{pH}$ and turbidity of the water. Current traditional water treatment systems use jar tests to determine coagulant doses. A jar test is an experimental technique in which a sample of water to be treated is poured into a series of beakers and different amounts of coagulant are added to the jars. It is an empirical process that involves the manual calculation of the relationship between the parameter given and selection. As a result, the Jar test is often overlooked. Furthermore, if conducted too often, Jar testing will consume a lot of chemicals for testing, and it also requires experience to obtain good results in determining the required coagulant dosage [3]. Therefore, this study tries to set up an accurate nonlinear mathematical model based on multivariate analysis to determine the WTPs optimum alum dose that represents the canal water quality dynamic characteristics soil.

\section{STUDY AREA}

The study area includes two selected WTPs along Ismailia Canal: Al Amerya (Latitude: 30 06 $6^{\prime} 41^{\prime \prime}$ and Longitude: $31^{\circ} 16^{\prime} 22^{\prime \prime}$ ) and Mostorud WTP (Latitude: $30^{\circ}$ $09^{\prime} 55^{\prime \prime}$ and Longitude: $31^{\circ} 17^{\prime} 36^{\prime \prime}$ ), Figure (1). The mean potable water productions of Al Amerya and Mostorud WTPs are 650,000m3/day and 950,000m3/day respectively. Moreover, these WTPs are considered the main sources of potable water for various Cairo governorates Northern and Eastern districts [4].

\section{MATERIAL and METHODS}

\section{A. Model Building}

This study aims to create a suitable model for study's WTPs coagulant consumption that requires identifying the major surface water quality affecting factors. To find out the major factors that directly affect the optimum alum doses, a step-by-step filtering by carrying out the Jar test data collection and operated actual data in 2019 at both of AlAmerya and Mostorud WTPs. Moreover, to avoid multi collinearity problems, all filtered factors were considered in the multivariate analysis based on regression models. 


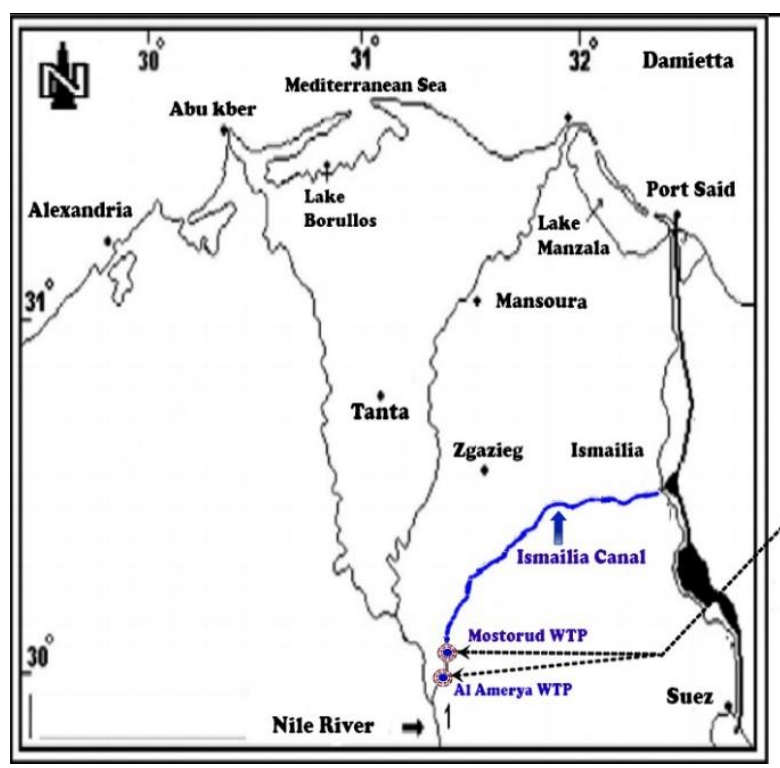

Fig. 1: Al Amerya and Mostorud WTPs Locations

Therefore, nonlinear regression will be developed according to equation (1), equation (2), and equation (3), [58]. Where $y$ is the unit coagulant consumption; $x i$ is an influencing factor for coagulant consumption; c is constant; ci is the weight of nonlinear regression impact factor.

While, Equation (2) and Equation (3) are the reformulations for equation (1) through the logarithmic form:

$$
\begin{aligned}
& (y+\delta)=c \cdot\left(x_{1}+\delta\right)^{c_{1}} \cdot\left(x_{2}+\delta\right)^{c_{2}} \cdot\left(x_{3}+\delta\right)^{c_{3}} \\
& \log (y+\delta)=\dot{c}+c_{1} \cdot \log \left(x_{1}+\delta\right)+c_{2} \cdot \log \left(v_{2}+\delta\right)+ \\
& \cdots+c_{p} \cdot \log \left(v_{p}+\delta\right)
\end{aligned}
$$

where, $\mathrm{c} /=\log (\mathrm{c})$

However, for model structure building and optimum coagulant dose prediction, three dominant parameters for raw surface water quality characteristics (Temperature, $\mathrm{pH}$, and Turbidity) are selected as dependent variables interrelating with the optimum coagulant dosage as an independent variable [9-11].

\section{B. Model Alternatives Output Evaluation}

After developing various model's alternatives, two main evaluating and comparison statistical tests to choose the most convenient alternative are applied: -

\section{- ANOVA test}

It is applied to models to determine if the difference between measured and simulated alum dose is significant or not.

II- Euclidian distance method

In this study, the important of applying this method is to extract the most suitable model alternative regarding its ability for observed data accurate representation. However, the target suitable model alternative that has the least Euclidian distances value according to equation (4):

Euclidian distance $=\sum_{k=0}^{n}\left(Y_{\text {observed }}-Y_{\text {measured }}\right)^{2}$

where $\mathrm{Y}_{\text {observed }}$ is the observed alum dose for jar test and $\mathrm{Y}_{\text {measured }}$ is the simulated alum dose.

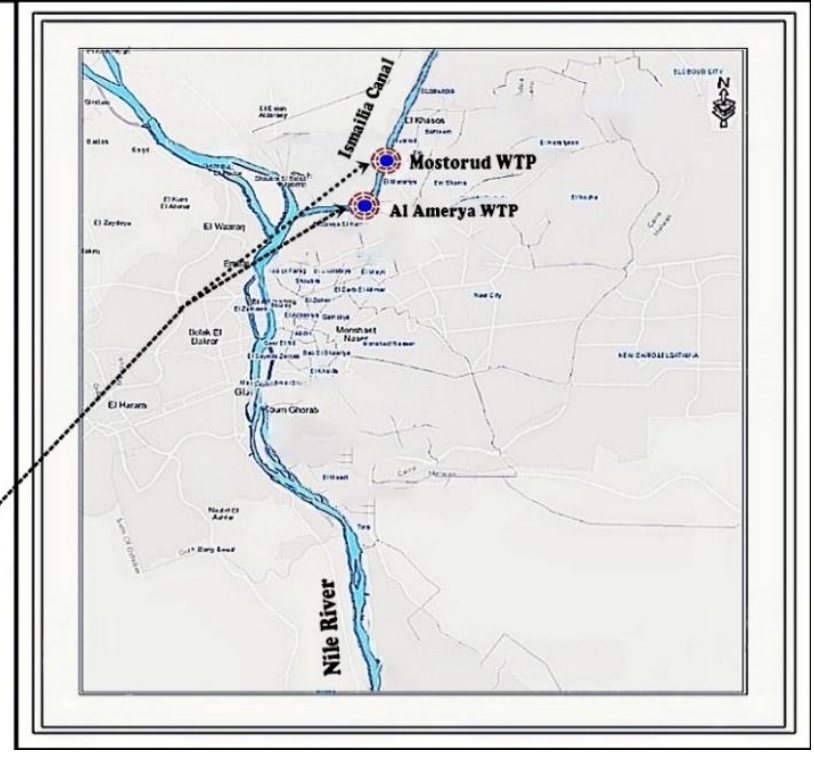

\section{Model Validation Statistics}

After that, model validation statistics were implemented to evaluate its prediction accuracy. Three statistical measures are chosen to evaluate the errors in the optimum alum dose simulated results:

-Relative Mean Absolute Error (MAE) rel

The optimum value of $\mathrm{MAE}_{\text {rel }}$ for best fit simulated with regarding to the observed is zero data, it can be calculated according to Equation (5) and Equation (6): -

$$
\begin{aligned}
& M A E=\left[\frac{1}{n} \sum_{i=1}^{n}\left|Y_{\text {Observied }}-Y_{\text {Simulated }}\right|\right] \\
& (M A E)_{\text {rel }}=\frac{M A E}{\overline{Y_{\text {Observied }}}}
\end{aligned}
$$

where $\mathrm{Y}_{\text {observed }}$ is the observed alum dose for jar test and Ymeasured is the simulated alum dose.

\section{- Percent Bias (PBIAS)}

The most convenient value for PBIAS is zero, it can be calculated according to Equation (7): -

PBIAS $=100 * \frac{\sum_{i=1}^{n}\left(Y_{\text {Observied }}-Y_{\text {Simulated }}\right)}{\sum_{i=1}^{n} Y_{\text {Observied }}}$

\section{- Nash-Sutcliffe Efficiency (NSE)}

The value of NSE equal to 1.0 is the optimal value. While results between zero and 1.0 are within acceptable performance limits, NSE is calculated according to Equation (8).

$$
N S E=1-\left[\frac{\sum_{i=1}^{n}\left(Y_{\text {Observied }}-Y_{\text {Simulated }}\right)^{2}}{\sum_{i=1}^{n}\left(Y_{\text {Observied }}-\overline{Y_{\text {Observied }}}\right)^{2}}\right]
$$

\section{RESULTS and DISCUSSIONS}

At the first step, the raw water samples of the selected coagulant consumption dominant parameters are assessed to evaluate their mean annual values during various seasons through year 2019. Table 1 shows the mean annual results of Temperature (Temp), pH, and Turbidity (Turb), for both Al Amerya and Mostorud WTPs. 
Table 1 . Mean raw water quality dominant variable

\begin{tabular}{|c|c|c|}
\hline $\begin{array}{c}\text { Mean Annual Raw Water } \\
\text { Quality Dominant Variable }\end{array}$ & $\begin{array}{c}\text { Al Amerya } \\
\text { WTP }\end{array}$ & Mostorud WTP \\
\hline Temp (0C) & $23.65 \pm 4.56$ & $23.74 \pm 3.84$ \\
\hline $\mathrm{pH}$ & $8.32 \pm 0.26$ & $8.36 \pm 0.31$ \\
\hline Turb (NTU) & $14.98 \pm 5.36$ & $12.78 \pm 5.78$ \\
\hline
\end{tabular}

It is obvious from the results of the mean annual raw water quality dominant variables that there are relatively noted variations in turbidity levels during various seasons of the year. However, two ranges of turbidity (Turb $<15$ NTU and $15 \mathrm{NTU} \leq$ Turb $\leq 30 \mathrm{NTU}$ ) are proposed for developing optimum coagulant dose to satisfy the model result in accuracy through each of the validated turbidity ranges. Meanwhile, according to the field sampling inputs that taken from the two water treatment plants, many model alternatives were developed to determine the optimum coagulant dose as the output. The six developed alternatives for alum simulation are:

Alum (Alt1) $=\mathrm{C}_{1}+\mathrm{C}_{2} *(\mathrm{pH})+\mathrm{C}_{3} *(\mathrm{pH})^{2}+\mathrm{C}_{4} *(\text { Turb })^{2}$

$\operatorname{Alum}_{(\text {Alt2) }}=\mathrm{C} 1 *(\mathrm{pH})+\mathrm{C} 2 *(\mathrm{pH})^{2}+\mathrm{C}_{3} *(\mathrm{Turb})^{2}$

$\operatorname{Alum}_{(\mathrm{Alt} 3)}=\mathrm{C}_{1}+\mathrm{C}_{2} *(\mathrm{pH})+\mathrm{C}_{3} *($ Temp $)+\mathrm{C}_{4} *($ Turb $)+$ $\mathrm{C}_{5} *(\text { Temp })^{2}+\mathrm{C}_{6} *(\mathrm{Temp}) *(\mathrm{pH})+\mathrm{C}^{7 *}($ Temp $) *($ Turb $)$ $+\mathrm{C}_{8} *(\mathrm{pH})_{2}+\mathrm{C}_{9} *(\mathrm{Turb}) *(\mathrm{pH})+\mathrm{C}_{10} *(\mathrm{Turb})^{2}+\mathrm{C}_{11} *($ Temp $)$ $*(\mathrm{pH}) *(\mathrm{Turb})$.

$\operatorname{Alum}_{(\text {Alt } 4)}=\mathrm{C}_{1} *($ Temp $)+\mathrm{C}_{2} *($ Turb $)+\mathrm{C}_{3} *(\mathrm{pH})$.

$\operatorname{Alum}_{(\mathrm{Alt5})}=\mathrm{C} 1+\mathrm{C}_{2} *(\mathrm{pH})+\mathrm{C}_{3} *(\mathrm{Temp})+\mathrm{C}_{4} *($ Turb $)$

Alum (Alt6) $=\mathrm{C}_{1} *(\mathrm{pH})+\mathrm{C}_{2} *($ Temp $)+\mathrm{C}_{3} *($ Turb $)+$ $\mathrm{C}_{4} *(\text { Temp })^{2}+\mathrm{C}_{5} *(\mathrm{Temp}) *(\mathrm{pH})+\mathrm{C}_{6} *($ Temp $) *(\mathrm{Turb})+\mathrm{C}_{7}$ $*(\mathrm{pH})^{2}+\mathrm{C}_{8} *(\mathrm{Turb}) *(\mathrm{pH})+\mathrm{C}_{9} *(\mathrm{Turb})^{2}+\mathrm{C}_{10} *(\mathrm{Temp}) *(\mathrm{pH})$ * (Turb)

After developing the various model alternatives output, a complete comparison between them was implemented. In addition to that, two main statistical tests were applied to satisfy the model alternatives output accuracy about the observed data. Thus, ANOVA test is performed to check the significant difference exists between models and observed data. Moreover, the Euclidian distance method is also applied to determine the most convenient model in regarding to the accurate representation of the dominant variables. Table (2) illustrates the six-model alternative's output that proposed to predict the alum optimum dose involved in the turbidity ranges (Turb $<15 \mathrm{NTU}$ and $15 \mathrm{NTU} \leq$ Turb $\leq 30 \mathrm{NTU}$ ) for Al Amerya and Mostorud WTPs.

It can be noted that the Alt 3 has the minimum Euclidian distance value for both levels of turbidity (Turb $<15$ NTU and $15 \mathrm{NTU} \leq$ Turb $\leq 30 \mathrm{NTU}$ ) compared with the others developed alternatives. However, it was recommended to use this alternative for determining the optimum aluminum sulfate dose for both Al Amerya and Mostorud WTPs. After that, a monthly based comparison between Alum Alt3 and the observed alum dose for another set of data for year 2018 in the two cases of turbidity ranges for both Al Amerya and Mostorud WTPs, Figure 1.
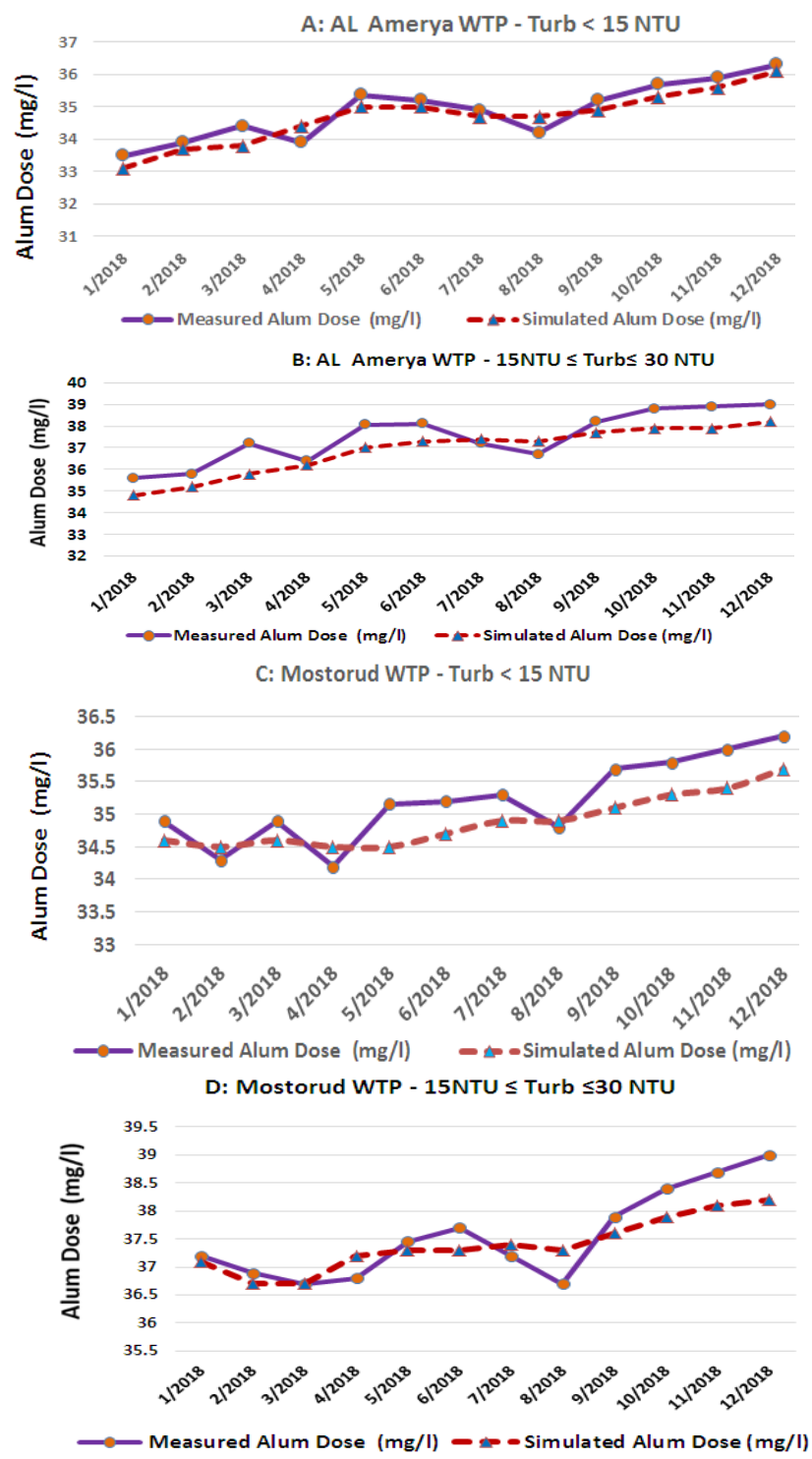

Fig. 1: Comparison between simulated and observed

It is obvious that during the winter, the canal water flow regime may be altered, and rain will entangle the soil wherever it passes, bringing all of the debris to the surface water upstream of the two WTPs. Moreover, the flow rate of the river usually varies when the rain tends to mix and fluctuate the sediments in the canal bed. These raise the relative turbidity levels in the winter season compared with other seasons of the year and lead to an increase in the required alum doses for treatment process at the two WTPs.

Moreover, to ensure the developed model (Alt3) validation accuracy in the specified turbidity ranges during yearly season's variation, three statistics measures are applied based on the comparison concepts between measured alum dose obtained from jar tests and the simulation alum dose developed from the model output as shown in table (3). 
Table 2. Model alternatives statistics

\begin{tabular}{|c|c|c|c|c|c|c|c|c|}
\hline \multicolumn{3}{|c|}{ Alternative } & Alt1 & Alt2 & Alt3 & Alt4 & Alt5 & Alt6 \\
\hline \multirow{2}{*}{ 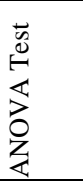 } & I & \multirow{3}{*}{ 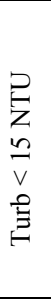 } & 0.000297 & 0.000238 & 0.002946 & 0.001528 & 0.000092 & 0.001043 \\
\hline & 工 : & & 3,85090 & 3,85090 & 3,85090 & 3,85090 & 3,85090 & 3,85090 \\
\hline \multicolumn{2}{|l|}{ 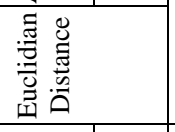 } & & 692.444 & 713.312 & 616.897 & 697.639 & 697.829 & 661.875 \\
\hline \multirow{2}{*}{ 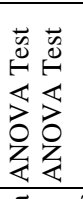 } & L & \multirow{3}{*}{ 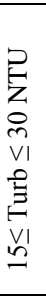 } & 0.560230 & 0.621728 & 0.563838 & 0.639630 & 0.584672 & 0.496728 \\
\hline & 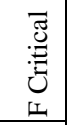 & & 3,932440 & 3,932440 & 3,932440 & 3,932440 & 3,932440 & 3,932440 \\
\hline \multicolumn{2}{|c|}{ 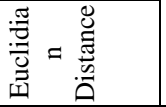 } & & 278.923 & 298.497 & 175.763 & 287.998 & 286.565 & 193.044 \\
\hline
\end{tabular}

Table 3. Model validation accuracy statistics

\begin{tabular}{|c|c|c|c|c|}
\hline WTP & Turbidity Range & MAE rel & PBIAS & NSE \\
\hline \multirow{2}{*}{$\begin{array}{c}\text { Al- } \\
\text { Amerya }\end{array}$} & Turb $<15$ NTU & 0.08 & 0.17 & 0.89 \\
\cline { 2 - 5 } & $\begin{array}{c}15 \text { NTU } \leq \text { Turb } \leq 30 \\
\text { NTU }\end{array}$ & 0.19 & 0.23 & 0.81 \\
\hline \multirow{2}{*}{ Mostorud } & Turb $<15$ NTU & 0.13 & 0.21 & 0.82 \\
\cline { 2 - 5 } & $\begin{array}{c}15 \text { NTU } \leq \text { Turb } \leq 30 \\
\text { NTU }\end{array}$ & 0.23 & 0.25 & 0.79 \\
\hline
\end{tabular}

It is clear that Alt3 satisfies the compliance with the observed data representation and it can be selected to predict the dose of the aluminum sulfate in both Al Amerya and Mostorud WTPs. However, the results show that the alum actual dose and their corresponding simulated values are very close values

\section{CONCLUSION}

- Most water treatment plants in Egypt try to achieve optimum dosages of alum doses, so jar tests must be implemented continuously per day especially in the cases of water source turbidity fluctuation to get the optimum alum dosage and that influenced in getting drinking water with more quality.

- In this study the optimum dosages of Alum are determined by using the nonlinear regression modeling for two water treatment plants named Al Amerya and Mostorud WTPs along the Ismailia canal.

- The models for the two treatment plants, Al Amerya and Mostorud WTPs, showed relatively high prediction accuracy. This could be mainly explained due to the interaction effect of dominant parameters being modeled and the simulated alum dose.

- This study serves as a reminder of the importance of continuously assessing the convenience of Ismailia canal as surface raw water source for potable water treatment.

- One of the advantages of the developed model is that there will be no need for jar testing again, it also helps in reducing dosing estimation error and ensuring quality of treatment process.

- The use of nonlinear regression modeling approach to determine the best approach of predicting chemical dosage during treatment is hereby encouraged, rather than reliance on a single model.

\section{REFERENCES}

[1] Geriesh, M. H., Stueben, D., Berner, Z., Ibraheim, M., 2004. Deficiencies of Simple Technologies in Surface Water Purification: A Case Study of Surface Water Treatment for Drinking Purposes at Suez City, Egypt. The International Conference of Geology of Arab World (GAW 7). Cairo, Egypt, p.429-437.

[2] Montgomery, J. M. Water treatment principles and design, John Wiley, New York. 1985, 2-3.

[3] 3- Ali, Muyibi, Salleh, and Alam, 2010. Production of Natural Coagulant from Moringa Oleifera Seed for Application in Treatment of Low Turbidity Water, Journal of Water Resource and Protection, 3(2).

[4] Holding Company for Drinking Water and Sanitation, Egypt, Annual Report, 2017.

[5] Kowal and Mackiewicz. The effect of water temperature on the course of alum coagulation on colloidal particles in water. Env. Prot. Eng. 1975;1(1):63-70.

[6] Bakker; van Duist, Schagen, K.; Vreeburg, J.; and Rietveld, Improving the performance of water demand forecasting models by using weather input. Procedia Eng. 2014, 70, 93-102.

[7] Carvalho; Marques; Berg, S. A meta-regression analysis of benchmarking studies on water utilities market structure. Util. Policy 2012, 21, 40-49.

[8] Candelieri, A. Clustering and Support Vector Regression for Water Demand Forecasting and Anomaly Detection. Water 2017, 9, 224.

[9] Zularisam, Ismail, Salim, and. Sakinah, Application of coagulation-ultrafiltration hybrid process for drinking water treatment: optimization of operating conditions using experimental design, Sep. Purif. Technol; 2009, 65 (2), 193.

[10] Aguilar, Saez, Llorens, Soler, Ortuno, Meseguer, and Fuentes, Improvement of coagulation- flocculation process using anionic polyacrylamide as coagulant aid, Chemosphere; 2005, 58 (1), 47.

[11] Gagnon, Grand jean, and Thibault, Modeling of coagulant dosage in water treatment plant. Artif. Intell. Eng., 11(4), 401-404 (1997). 